ANA CAROLINA ALBUQUERQUE DE BARROS

\title{
CULPABILIDADE NO DIREITO PENAL JUVENIL
}

Dissertação de mestrado

Orientador: Professor Titular Alamiro Velludo Salvador Netto

Universidade de São Paulo

Faculdade de Direito

São Paulo/SP

2019 
ANA CAROLINA ALBUQUERQUE DE BARROS

\section{CULPABILIDADE NO DIREITO PENAL JUVENIL}

Dissertação apresentada à Banca Examinadora do Programa de Pósgraduação em Direito, da Faculdade de Direito da Universidade de São Paulo, como exigência parcial para obtenção do Título de Mestre em Direito, na área de concentração Direito Penal, sob orientação do Professor Titular Alamiro Velludo Salvador Netto.

Universidade de São Paulo

Faculdade de Direito

São Paulo/SP

2019 
Autorizo a reprodução e divulgação total ou parcial deste trabalho, por qualquer meio convencional ou eletrônico, para fins de estudo e pesquisa, desde que citada a fonte.

Catalogação da Publicação

Serviço de Biblioteca e Documentação

Faculdade de Direito da Universidade de São Paulo

Barros, Ana Carolina Albuquerque de
Culpabilidade no Direito Penal Juvenil/ Ana Carolina
Albuquerque de Barros; orientador Alamiro Velludo Salvador
Netto -- São Paulo, 2019. 186.
Direito Penal) - Faculdade de Direito, Universidade de São
Paulo,2019.
Direito Penal Juvenil. $2 . \quad$ Culpabilidade.

3. Imputabilidade. 4. Menoridade. I. Alamiro Velludo Salvador

Netto, orient. II. Culpabilidade no Direito Penal Juvenil. 


\section{CULPABILIDADE NO DIREITO PENAL JUVENIL}

Dissertação apresentada à Banca Examinadora do Programa de Pós-graduação em Direito, da Faculdade de Direito da Universidade de São Paulo, como exigência parcial para obtenção do Título de Mestre em Direito, na área de concentração Direito Penal, sob orientação do Professor Titular Alamiro Velludo Salvador Netto.

BANCA EXAMINADORA

Presidente:

Professor Titular Alamiro Velludo Salvador Netto

$1^{\circ}$ Examinador (a):

$2^{\circ}$ Examinador (a):

$3^{\circ}$ Examinador (a): 
Aos meus pais, pelo amor incondicional. 
Barros, Ana Carolina Albuquerque de. Culpabilidade no Direito Penal Juvenil. 2019. 186 p. Mestrado Faculdade de Direito. Universidade de São Paulo, São Paulo, 2019.

\section{RESUMO}

O presente trabalho tem por objetivo analisar a compatibilidade da culpabilidade com o Direito Penal Juvenil, o que é feito a partir da análise dos principais entraves a esta posição. O ponto de partida é a reafirmação do sistema de responsabilização previsto no Estatuto da Criança e do Adolescente como um verdadeiro Direito Penal Juvenil, o que se faz a partir da análise do atual tratamento jurídico dispensado à criança e ao adolescente, bem como das etapas que a precederam. Reafirmado o Direito Penal Juvenil, o trabalho percorre a evolução dogmática do conceito de culpabilidade, o que culmina na análise da influência que a racionalidade penal moderna tem sob este conceito. Apresentadas as principais conceituações modernas desta categoria, parte-se para a análise da operacionalidade do mesmo no Direito Penal Juvenil, bem como da necessária adequação dogmática que enseja.

Palavras chave: Culpabilidade; Direito Penal Juvenil; Garantismo; Imputabilidade; Inimputabilidade; Medidas socioeducativas. 
Barros, Ana Carolina Albuquerque de. Culpabilidade no Direito Penal Juvenil. 2019. 186 p. Mestrado Faculdade de Direito. Universidade de São Paulo, São Paulo, 2019.

\begin{abstract}
The present work aims to analyse the compatibility of the culpability with the Juvenile Criminal Law, which is done from the analysis of the main obstacles to this position. The starting point is the reaffirmation of the accountabillity system provided by the Child and Adolescent Statute as a true Juvenile Criminal Law, what is done from the analysis of the present legal treatment dispensed to the child and adolescent, as well as the steps that preceded it. Reaffirmed the Juvenile Criminal Law, the work ranges the dogmatic evolution of the concept of culpability, that culminate in an analysis of the influence that the modern criminal rationality have about this concept. Presented the main modern conceptions of this class, part for an analysis of the operability of the same in the Juvenile Criminal Law, as well as the necessary dogmatic adequacy that causes.
\end{abstract}

Key-Words: Culpability; Juvenile Criminal Law; Garantism; Imputability; Inimputability; Educational Measures. 


\section{SUMÁRIO}

INTRODUÇÃO. .11

CAPÍTULO 1 - BREVES CONSIDERAÇÕES SOBRE O SISTEMA DE RESPONSABILIZAÇÃO DE ADOLESCENTES............................................17

1.1 As etapas da responsabilização penal juvenil......................................................17

1.1.1 Etapa de caráter penal indiferenciado................................................................17

1.1.2 Etapa de caráter tutelar...............................................................................19

1.1.3 Etapa de caráter garantista............................................................................24

1.1.3.1 Principais características da etapa de caráter garantista.........................................27

1.2 A etapa de caráter garantista e os sistemas de responsabilidade penal juvenil......30

CAPÍTULO 2 - A BASE DOGMÁTICA DO DIREITO PENAL JUVENIL............39

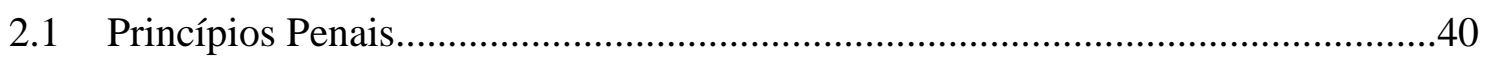

2.1.1 Princípio da Legalidade.............................................................................

2.1.2 Princípio da Humanidade ………………………………………………....4

2.1.3 Princípio da Intervenção Mínima ……………………………………………......45

2.1.4 Princípio da Proporcionalidade …………………………………...................

2.1.5 Princípio da Culpabilidade .........................................................................50

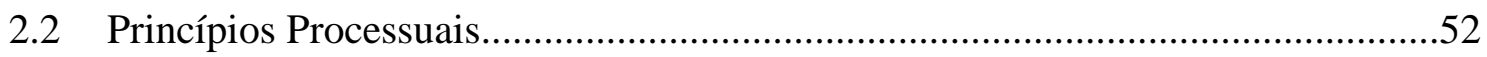

2.3 Princípios do Direito da Criança e do Adolescente...............................................53

2.3.1 Princípio da condição peculiar de pessoa em desenvolvimento..............................55

2.3.2 Princípio do melhor interesse da criança e do adolescente.....................................57

2.4 O sistema brasileiro de responsabilidade penal de adolescentes............................59

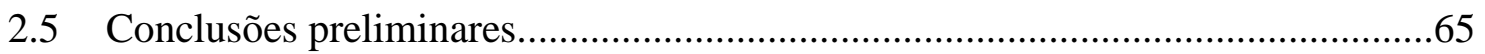

CAPÍTULO 3 - O EVOLUÇÃO DOGMÁTICA DA CULPABILIDADE: UM CAMINHO RUMO À INDIVIDUALIZAÇÃO DA CULPA............................73

3.1 A culpa em Karl Binding..................................................................................73

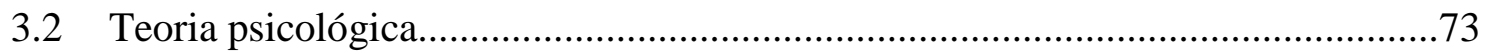

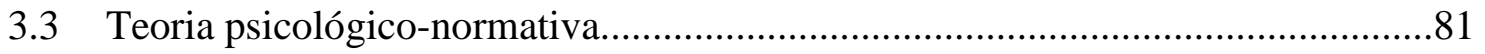

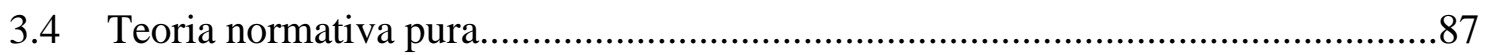

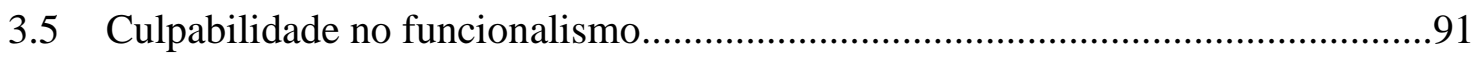


3.5.1 Roxin e a culpabilidade como limite à prevenção...........................................92

3.5.2 Jakobs e a culpabilidade como infidelidade ao direito........................................101

3.5.3 Muñoz Conde e a culpabilidade como motivabilidade......................................109

3.6 Os pilares da culpabilidade e sua indemonstrabilidade........................................115

CAPÍTULO 4 - CULPABILIDADE NO DIREITO PENAL JUVENIL ................119

4.1 Pilares da culpabilidade no Direito Penal Juvenil...................................................119

4.1.1 O menor (in)culpável: vulnerabilidade, seletividade e periculosidade.................120

4.1.2 A ideia de bem jurídico universal versus a pluralidade referencial normativa do

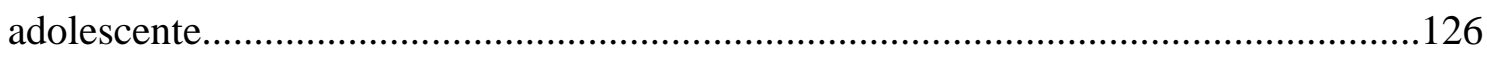

4.1.3 A pretensa indissociabilidade entre ato infracional e medida socioeducativa......130

4.1.3.1 Para que punir? Retribuição ou educação na Justiça Juvenil? ...........................130

4.1.3.2 Finalidades da medida socioeducativa à luz das teorias da pena......................132

4.2 Releitura da culpabilidade à luz dos princípios do Direito da Criança e do Adolescente: a necessária adequação dogmática.........................................................141

4.2.1 Fundamentos materiais para a culpabilidade no Direito Penal Juvenil.................146

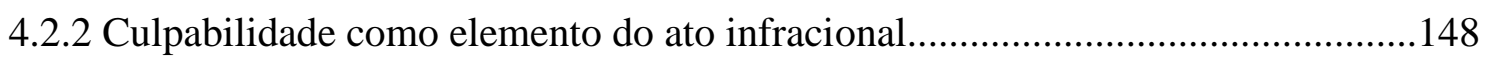

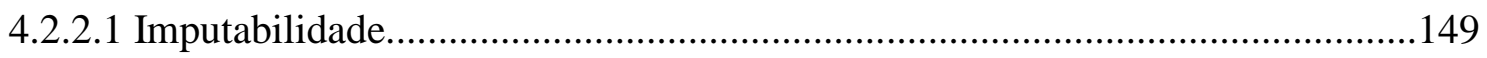

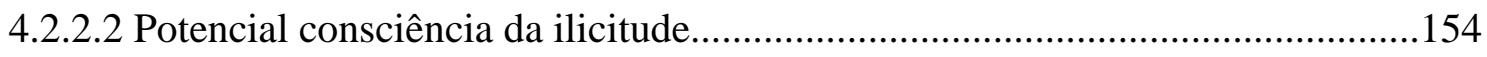

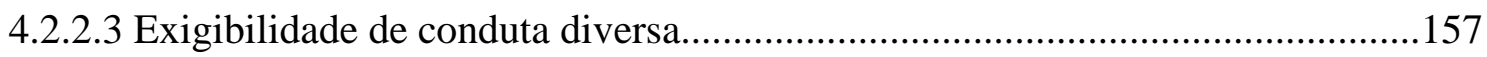

4.2.3 Culpabilidade como circunstância judicial de aplicação da medida socioeducativa.

.160

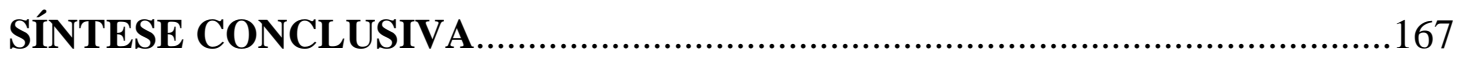

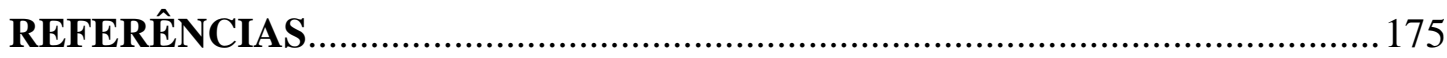





\section{INTRODUÇÃO}

As ideias de infância e adolescência não são contemporâneas entre si, e, antes de serem explicadas por teorias psicológicas, são melhor explicadas pelo enfoque histórico, que as apresenta como resultado de uma construção social complexa, relacionada a condições não só de caráter estrutural, mas também à sucessivas revoluções no campo dos sentimentos ${ }^{1}$.

A conscientização de que a infância seria uma etapa especial e diferenciada da vida data do século XVII. ${ }^{2}$ Ainda na Idade Média, no entanto, não é possível identificar uma percepção das distinções da infância em relação aos adultos. Essa afirmação é possível de ser feita a partir de uma reconstrução histórica, que considere, por exemplo, que na representação artística da Idade Média, a figura da criança era inexistente, ou também, pela análise do tratamento dispensado ao infanticídio que, ao longo do tempo, partiu de uma conduta socialmente aceita para uma conduta intolerável.

Nesse processo histórico deve-se destacar o papel da escola que, organizada a partir dos pilares da vigilância permanente, da obrigação de denúncia e da imposição de penas corporais, se apresentou como modeladora do indivíduo.

Ao seu turno, a ideia de adolescência pode ser verificada a partir do final do século XIX e início do século XX, coincidindo com a Revolução Industrial e a intensa utilização de mão de obra infantil nas linhas de produção ${ }^{3}$. É, pois, uma concepção mais próxima da contemporaneidade, e, igualmente à infância, é melhor explicada como uma construção social, embora seja inegável a existência de fatores biopsicológicos.

Considerando-se a distância temporal entre uma concepção e outra, vê-se que o tratamento jurídico dispensado a estes grupos não possuía qualquer distinção, estando centralizado na figura da criança. Assim, é que os documentos internacionais, em sua maioria, tratam sobre os direitos da criança, englobando a aplicação dos mesmos à categoria dos adolescentes.

\footnotetext{
${ }^{1}$ MÉNDEZ, Emilio García. Para uma historia del control penal de la infancia: la informalidade de los mecanismos formales de control social. In RAMÍREZ, Juan Busto. Um Derecho Penal del Menor. Santiago de Chile: Editorial Jurídica ConoSur Ltda., 1992, p. 155;

${ }^{2}$ DOMINGO, Cíntia Oliveira. Adolescente e maioridade penal: reflexões sobre violência e prevenção à luz da proteção integral. Curitiba: Juruá, 2016, p. 25.

${ }^{3}$ SARAIVA, João Batista Costa. Compêndio de Direito Penal Juvenil. 3 ed. rev., e ampl. Porto Alegre: Livraria do Advogado, 2006, p. 30-32;
} 
Inicialmente, a criança não era vista como um sujeito de direitos, e assim, não possuía um referencial jurídico voltado para si. No entanto, em que pese fossem encarados como seres absolutamente incapazes, era reconhecido que, em determinados campos, suas ações causavam resultados juridicamente relevantes, notadamente no campo do Direito Penal, demandando, portanto, respostas estatais.

É nesse sentido, que se pode afirmar que o Direito da Criança e do Adolescente se confunde em seus primórdios com a questão da responsabilidade penal dos mesmos. Ademais, é possível observar que não apenas o jovem infrator foi objeto de um referencial jurídico, mas também o jovem abandonado, ou como se afirmava à época, em situação irregular. Esses dois arquétipos de jovens, que se confundiram em muitas oportunidades, acionavam respostas idênticas, para casos distintos, conformando um conjunto de regras específicas, voltadas a uma parcela da infância e juventude.

Essa relação entre direitos e garantias e a responsabilização penal dos adolescentes pode ser observada também na atualidade, na medida em que o debate sobre a maior ou menor responsabilização penal destes indivíduos, e todas as nuances dele surgidas, se apresenta como um termômetro da efetivação de direitos e garantias dessa parcela da populaçãó ${ }^{4}$.

Embora o Estatuto da Criança e do Adolescente seja uma legislação reconhecidamente avançada no que concerne à efetivação de direitos e garantias de crianças e adolescentes, certo é que mesmo passados quase 30 anos de sua promulgação, a concretização dos direitos nele estampados não se deu de maneira satisfatória, sobretudo no que tange ao sistema de responsabilização de adolescentes.

Isso porque, resquícios de uma lógica tutelar e correcionalista ainda influenciam a atuação da Justiça Juvenil, contrariando, a partir da deturpação dos princípios do Direito da Criança e do Adolescente, a essência do sistema de responsabilização trazido pelo ECA.

\footnotetext{
${ }^{4}$ Nesse sentido, Emilio García Méndez alerta que "a pesar de su dimensión cuantitativa reducida, la cuestión de los adolescentes en conflito con la ley, posee un carácter contaminante negativo sobre el conjunto de las polítias sociales. Descubrir tendencias y analizar comportamentos políticos en este campo, constituye uno de los termómetros mas sensibles para entender la dimensión política de la cuestión social em América Latina. Entender hoy las vicissitudes y tendencias de la cuestión penal juvenil, constituye, a mi juicio, um elemento decisivo para tratar de entender hacia donde van los derechos de la infancia em América Latina." MÉNDEZ, Emilio Gárcia. Problemas centrales de la responsabilidad penal juvenil em America Latina. In Justiça Juvenil na Contemporaneidade. COSTA, Ana Paula Motta; e EILBERG, Daniela Dora (orgs). Porto Alegre: DM, 2015, p. 16 ;
} 
Nesse sentido, parte da doutrina tem proposto o reconhecimento de um Direito Penal Juvenil, com vistas a um maior controle da intervenção estatal sobre a esfera de liberdade dos adolescentes.

Contudo, apenas o reconhecimento formal deste Direito Penal Juvenil não é suficiente para, de maneira eficaz, conter o poder punitivo estatal. É preciso que se assegure, no momento da responsabilização de adolescentes a observância de garantias não apenas oriundas do Direito da Criança e do Adolescente, mas também de garantias de contenção, próprias do Direito Penal e Processual Penal.

Dentre os mecanismos de contenção que devem integrar este Direito Penal Juvenil, encontra-se a culpabilidade, categoria de complexa operacionalidade, que no Direito Penal tem a si atribuída a função de limite, fundamentação e gradação da pena.

Sua valoração no Direito Penal Juvenil permite o aprimoramento deste sistema de responsabilização, adequando-o à doutrina da proteção integral, impossibilitando que os resquícios da ideologia tutelar, fantasiados de pretensões pedagógicas, preponderem na Justiça Juvenil.

Todavia, a operacionalidade desta categoria no campo da responsabilização juvenil não depende de uma mera importação da estrutura atuante no Direito Penal. Se naquele sistema a culpabilidade já apresenta pontos controvertidos, normalmente atrelados a questão do livre arbítrio, no Direito Penal Juvenil sua tradicional conceituação se mostra incompatível.

Livre arbítrio, universalidade dos bens jurídicos, imputabilidade, reprovabilidade: estes aspectos, quando analisados a partir da perspectiva tradicional, inviabilizam de plano a análise da culpabilidade.

Neste contexto, o presente trabalho se propõe a investigar em que medida a culpabilidade pode ser considerada também no Direito Penal Juvenil, bem como se será possível uma adequação dogmática desta categoria às peculiaridades do Direito da Criança e do Adolescente.

Para tanto o trabalho divide-se em três frentes: a primeira direcionada à análise do Direito Penal Juvenil; a segunda relacionada à análise da evolução dogmática do conceito de culpabilidade; por fim, a terceira voltada à verificação da possibilidade de uma adequação dogmática da culpabilidade com o Direito Penal Juvenil. 
O primeiro e segundo capítulo cuidam da reafirmação do sistema de responsabilização de adolescentes inaugurado pelo ECA como um Direito Penal Juvenil.

No primeiro capítulo, são analisadas as etapas de responsabilização dos adolescentes infratores, e a partir das características da etapa garantista é analisada a compatibilidade desta com o Direito Penal Juvenil.

Já no segundo capítulo, o trabalho apresenta a base dogmática do Direito Penal Juvenil, composta por princípios do Direito Penal e Processual Penal e por princípios do Direito da Criança e do Adolescente. Amparado nesta base principiológica, o trabalho busca destrinchar a estrutura do sistema de responsabilização presente no ECA, e ao final analisa brevemente a crise que esta legislação, sobretudo no que toca ao seu sistema de responsabilização, tem enfrentado.

Em um segundo momento, o trabalho se propõe a percorrer a trajetória do conceito de culpabilidade, de modo a observar em que medida a tradicional conceituação desta categoria se compatibiliza com as peculiaridades do Direito Penal Juvenil.

Para tanto são analisadas as teorias psicológico, psicológico-normativa e normativa pura da culpabilidade, bem como as três principais vertentes do pensamento funcionalista, representadas pelas teorias de Roxin, Jakobs e Muñoz Conde.

Apresentadas as principais conceituações sobre a culpabilidade, o trabalho dedica espaço a uma breve análise acerca da influencia da racionalidade penal moderna nestes conceitos.

A partir disso será possível analisar em que medida há uma culpabilidade operante no Direito Penal Juvenil, qual o seu conteúdo material e quais as necessárias adequações desta categoria à específica estrutura do sistema de responsabilização de adolescentes vigente em nosso ordenamento jurídico.

Assim, a primeira parte do quarto capítulo busca apresentar uma leitura adequada dos pilares da culpabilidade para o Direito Penal Juvenil, analisando-se o sujeito culpável deste sistema, o referencial normativo a que ele está sujeito, bem como a relação existente entre o ato infracional e a medida socioeducativa. Quanto a este último aspecto, o trabalho busca, a partir das teorias da pena, apresentar uma leitura da medida socioeducativa e suas finalidades mais adequada ao Direito Penal Juvenil, que proporcione uma responsabilização de adolescentes em conflito com a lei dentro de um marco democrático e garantista. 
No que se refere propriamente à culpabilidade e sua conceituação no Direito Penal Juvenil, o capítulo quatro assenta sua análise na responsabilidade enquanto fundamento material desta categoria. A partir desta perspectiva, o final do quarto capítulo dedica-se a uma adequação dogmática da categoria da culpabilidade em dois importantes aspectos: como elemento do ato infracional e como circunstância judicial de aplicação da medida socioeducativa.

Enquanto elemento do ato infracional, a culpabilidade enseja a análise da imputabilidade, da potencial consciência da ilicitude e da exigibilidade de conduta diversa. No âmbito do Direito Penal Juvenil estas questões assumem contornos específicos, que ensejam interpretações distintas da que são feitas no Direito Penal.

A imputabilidade, obstáculo aparente à análise da culpabilidade do adolescente, clama por uma interpretação distinta, afeita à culpabilidade materialmente fundamentada na responsabilidade. Sob esta ótica, ela não mais se apresenta enquanto um juízo negativo, e assim, é entendida como uma garantia do adolescente que ao mesmo tempo inabilita a incidência do Direito Penal aos menores de 18 anos, e habilita a incidência do Direito Penal Juvenil a estes indivíduos.

Tal qual a imputabilidade, as hipóteses de erro e de inexigibilidade de conduta precisam ser interpretadas de maneira compatível às peculiaridades do adolescente, considerando-se sua condição de sujeito em desenvolvimento, exposto a uma pluralidade de referenciais normativos.

No que se refere à culpabilidade enquanto circunstância judicial de aplicação de medida socioeducativa, o trabalho se propõe, ainda que sem pretensões de esgotar o tema, a analisar a operacionalidade desta categoria dentro do sistema trazido pelo ECA, identificando quais as balizas apresentadas pela legislação.

Em síntese, o trabalho busca identificar a compatibilidade da culpabilidade com o Direito Penal Juvenil a partir de uma interpretação mais adequada dos entraves que tradicionalmente se apresentam a esta posição. 



\section{SÍNTESE CONCLUSIVA}

1. O tratamento jurídico dispensado a crianças e a adolescentes historicamente esteve atrelado, de maneira preponderante, à responsabilização dos mesmos por práticas delitivas. Assim, a doutrina divide em três momentos distintos este tratamento jurídico: um de caráter penal indiferenciado, um de caráter tutelar e um de caráter garantista.

1.1. A etapa de caráter penal indiferenciado teve por base os princípios da escola clássica, em que o delito e a pena partiam de uma concepção positivista, sendo o primeiro visto como sintoma de periculosidade. Neste momento os menores de idade eram tratados tal qual adultos no que tange à responsabilização penal por seus atos. No Brasil, a faixa de inimputabilidade etária era bem menor oscilando entre 9 e 14 anos, a depender do período, e vigorava o critério do discernimento, pelo qual o inimputável em que se verificasse o discernimento, seria privado de sua liberdade.

1.2. A etapa de caráter tutelar, embora representasse um avanço no campo da responsabilização de crianças e adolescentes, já que diferenciava estes dos adultos, teve por característica a chamada doutrina da situação irregular, na qual jovens em conflito com a lei e jovens abandonados eram tratados da mesma forma e ensejavam a mesma resposta estatal. A base desta etapa foi o correcionalismo, que autorizou uma desmedida intervenção estatal na esfera de liberdade de crianças e adolescentes. A síntese desta etapa é a objetificação das crianças e adolescentes, tratadas pelo Estado como seres incapazes, bem como a divisão da infância em duas: a regular, de tutela da família, e a irregular, tutelada pelo Estado.

1.3. A etapa garantista, por sua vez, foi a superação das que a precederam. Tem por característica o reconhecimento das crianças e adolescentes como sujeitos de direitos fundamentais e é fruto de uma modificação progressiva em âmbito internacional no tratamento jurídico dispensado aos menores de 18 anos. Sua principal característica é a superação da doutrina da situação irregular, a partir da adoção de princípios como da proteção integral, da peculiar condição de pessoa em desenvolvimento, da absoluta prioridade e do melhor interesse da criança e do adolescente.

1.3.1. No Brasil, a síntese desta etapa é o Estatuto da Criança e do Adolescente que inaugurou um sistema de proteção e efetivação de direitos direcionado aos menores de 18 anos. No que diz respeito à responsabilização dos adolescentes em conflito com a lei, o ECA trouxe um subsistema de Direito Penal Juvenil, que é a intersecção entre os sistemas do ECA e do Direito Penal. 
1.4. O Direito Penal Juvenil tem por característica a aplicação de todas as garantias inerentes ao Direito Penal (sejam elas penais ou processuais) no âmbito da responsabilização de adolescentes - contexto em que também incidem todas as garantias do Direito da Criança e do Adolescente. Nesse sentido, o Direito Penal Juvenil atua como um sistema garantista e democrático, específico aos adolescentes, que tem por finalidade a contenção do poder punitivo estatal.

1.4.1. Seu reconhecimento, ainda que não seja pacífico na doutrina, é compatível com toda a estrutura inaugurada pelo ECA e funda-se na constante preocupação com o recrudescimento do tratamento dispensado aos adolescentes na Justiça Juvenil. Na mesma linha inserem-se aqueles que rechaçam a ideia do Direito Penal Juvenil, pois também esta parcela da doutrina teme o retorno às práticas arbitrárias contra os adolescentes. Disso desponta que a negativa ao Direito Penal Juvenil vem acompanhada, normalmente, de uma visão da medida socioeducativa algo substancialmente distinto da pena e, assim, incompatível com a categorização de sanção penal. Igualmente, a corrente que nega a compatibilidade do Direito Penal Juvenil o faz por sustentar certa incompatibilidade entre este e o Direito Penal, pois atribui ao último uma acepção distinta da científica.

1.4.2. Ocorre que medida socioeducativa não se distancia do que se entende por sanções penais. Carrega consigo uma conotação aflitiva e retributiva que, embora se concretize, em tese, a partir de projetos pedagógicos, não se afasta de sua natureza penal. Ademais, Direito Penal e Direito Penal Juvenil representam sistema e subsistema, de modo que o subsistema do Direito Penal Juvenil, incidente apenas aos indivíduos que estejam na faixa etária entre 12 e 18 anos, é o ponto de intersecção entre Direito Penal e ECA, do qual também é subsistema.

1.4.3. A inimputabilidade afasta apenas a incidência do Direito Penal, mas não veda a utilização das garantias de contenção do poder punitivo no âmbito do Direito Penal Juvenil.

2. O Direito Penal Juvenil tem como base dogmática um arcabouço principiológico que congrega princípios penais, processuais penais e de Direito da Criança e do Adolescente. Nesse sentido, a responsabilização de adolescentes pela prática de atos infracionais deve, necessariamente, observar os princípios da legalidade, humanidade, mínima intervenção, proporcionalidade, culpabilidade, devido processo legal (no qual inserem-se os demais princípios processuais penais), bem como os princípios do melhor interesse da criança e do adolescente e da peculiar condição de pessoa em desenvolvimento.

2.1. Estes princípios conferem unidade sistêmica ao Direito Penal Juvenil e atendem às exigências de segurança jurídica, pois possibilitam uma aplicação justa e proporcional do Direito também no âmbito da Justiça Juvenil. Ademais, a união dos princípios oriundos do 
Direito Penal com os princípios oriundos do Direito da Criança e do Adolescente tem por objetivo tornar a responsabilização de adolescentes pela prática de atos infracionais um campo extremamente limitado, impossibilitando arbitrariedades.

2.2. Embora o ECA tenha inaugurado um sistema afeito ao Direito Penal Juvenil, a prática tem demonstrado que ele sofre uma dupla crise, que afeta os campos da implementação e da interpretação. A crise de implementação está relacionada à ausência de estrutura para a efetivação dos direitos previstos pelo ECA. Já a crise de interpretação tem sido associada à leitura que se faz do sistema de responsabilização de adolescentes trazido pelo ECA.

2.2.1. A negação do Direito Penal Juvenil é a consequência mais evidente desta crise de interpretação. O sistema de responsabilização do ECA tem sido utilizado sem a observância das garantias penais e processuais, bem como tem-se utilizado os princípios do Direito da Criança e do Adolescente de maneira deturpada, como forma de legitimar punições claramente contrárias à lei. Isso porque impera na Justiça Juvenil resquícios da etapa tutelar, em que o adolescente era entendido como um indivíduo necessitado da tutela estatal. Essa visão de indivíduo incapaz é ainda encontrada na Justiça Juvenil, que atualmente convive com punições justificadas a partir do melhor interesse do adolescente ou da ausência de respaldo familiar.

2.3. Essa crise observada no Direito Penal Juvenil - consequência da negação do mesmo - pode ser lida como uma crise de legislação garantista, pois observamos um déficit entre o modelo constitucional e aquilo que se coloca em prática: desrespeita-se a lei, já que não se observam corretamente as normas previstas e, disso, decorre uma descaracterização do sistema como um todo, que se soma à ausência de meios eficientes para efetivação dos direitos e garantias nele previstos.

2.4. Essa crise, no entanto, não tem o condão de descaracterizar o Direito Penal Juvenil como legislação garantista que, não sendo reconhecido e corretamente operacionalizado, é incremento das deletérias consequências desta crise. Logo, apenas a reafirmação de todas as garantias que integram sua base dogmática é que será capaz de retirar o Direito Penal Juvenil do caminho de volta às práticas tutelares.

2.5. A culpabilidade é uma das garantias penais de contenção ao poder punitivo que deve integrar o Direito Penal Juvenil, porém não apenas em sua acepção principiológica, que veda a responsabilização objetiva latu sensu. É preciso que esta complexa categoria opere no Direito Penal Juvenil também como elemento do ato infracional e como circunstância judicial para a aplicação de medida socioeducativa. Apenas assim a responsabilização de adolescentes em conflito com a lei se dará de maneira garantista e democrática. 
2.5.1. A mera importação da culpabilidade do Direito Penal ao Direito Penal Juvenil, no entanto, não satisfaz as necessidades e peculiaridades deste especifico subsistema. É preciso, portanto, uma adequação dogmática desta categoria, para que sua operacionalidade não reste fadada ao fracasso.

3. A culpabilidade, ao longo do tempo, percorreu um caminho rumo a individualização da culpa que, inicialmente inseria-se numa perspectiva psicológica, na qual considerava-se apenas a relação de causalidade e a previsão ou possibilidade de previsão do resultado. Sua evolução passou pela inserção de uma perspectiva normativa atrelada à psicológica e que, ao fim, passou a ser puramente normativa, de modo que culpabilidade passou a ser a reprovação do autor do fato que, podendo, não agiu conforme a norma.

3.1. Com o pensamento funcionalista, a pena passa a ser analisada com vistas à prevenção dos delitos e, assim, a culpabilidade assume contornos distintos. Na visão de Roxin, se apresenta como limite à função de prevenção do Direito Penal; para Jakobs, cede lugar à prevenção puramente; e para Muñoz Conde, insere-se no marco da socialização.

3.2. A análise das diversas teorias da culpabilidade demonstra que permanece inalterada a visão do sujeito culpável, livre e racional, que comunga da universalidade das normas e dos bens jurídicos por elas tutelados, que caso lesionados implicam a aplicação de uma pena, muito embora estes pilares da culpabilidade sejam indemonstráveis.

4. A permanência da visão de um sujeito culpável, livre e racional, que comunga da universalidade das normas e dos bens jurídicos por elas tutelados, que caso lesionados implicam a aplicação de uma pena, além de influenciar negativamente a análise da culpabilidade no âmbito do Direito Penal, também se apresenta como um obstáculo a análise desta categoria do Direito Penal Juvenil. Isso porque o adolescente, sujeito culpável neste subsistema, pelas peculiaridades oriundas da fase de vida em que se encontra, é incompatível com esta visão.

4.1. O sujeito culpável da racionalidade penal moderna conforma o conceito de imputabilidade a partir de aspectos unicamente cognitivos e volitivos, afastando o adolescente desta categoria, o que implica na associação do mesmo ao conceito de periculosidade. É este estigma de sujeito perigoso que tem, historicamente, justificado a submissão do adolescente à tutela estatal, do que decorre sua vulnerabilidade e sua selecionabilidade pelas agências de criminalização secundária.

4.1.2. Ante a ausência de um conceito explícito de culpabilidade no ECA, e a partir da negação do Direito Penal Juvenil, a Justiça Juvenil tem se valido da periculosidade como equivalente da culpabilidade, a partir da consideração de elementos da personalidade e da conduta social do adolescente. 
4.2. A universalidade das normas e dos bens jurídicos por elas tutelados também não se compatibiliza com o adolescente, pois no âmbito da Justiça Juvenil é preciso considerar a pluralidade do referencial normativo de nossa juventude, associada ao fato de que o adolescente é sujeito em peculiar condição de desenvolvimento. Dessa forma, sua formação se dá a partir da assimilação de distintas interpretações das regras sociais, influências essas de fatores como família, origem social, etnia, comunidade, etc.

4.3. Na Justiça Juvenil observa-se, tal qual na racionalidade penal moderna, uma pretensa indissociabilidade entre ato infracional e medida socioeducativa. Contudo, essa visão é contrária a própria essência do Direito Penal Juvenil que, considerando o melhor interesse do adolescente e sua peculiar condição de pessoa em desenvolvimento, tem como alternativa a não aplicação de qualquer medida socioeducativa.

4.3.1. Atribui-se à medida socioeducativa não apenas uma finalidade pedagógica, mas também uma essência penal, ante sua inegável natureza retributiva, de modo que sua justificativa parte de um modelo combinatório entre retribuição e prevenção, inserindo-se no conjunto das sanções penais.

4.3.2. As teorias das penas, quando aplicadas ao Direito Penal Juvenil, deixam clara a sua incompatibilidade com as peculiaridades deste subsistema. A pretensa finalidade pedagógica da medida socioeducativa tem sido utilizada como pretexto para a intensificação da intervenção estatal na esfera de liberdade dos adolescentes. Nesse sentido, a prevenção especial a que tanto se alude não se sustenta, seja pela deturpação da finalidade, seja pelo fato de que não pode o Estado pretender, a partir de uma pena, educar.

4.3.3. Assim, a teoria agnóstica da pena é capaz de, no que concerne à medida socioeducativa, proporcionar alternativas de resolução destes conflitos, que sejam mais afeitas ao espírito do Direito da Criança e do Adolescente. No que tange à culpabilidade, uma perspectiva agnóstica da medida socioeducativa, desmonta a ideia de indissociabilidade entre ato infracional e sanção, o que abre espaço para uma discussão sobre a culpabilidade no Direito Penal Juvenil.

4.4. A mera importação da categoria da culpabilidade do Direito Penal para o Direito Penal Juvenil não é capaz de tornar operacionalizável esta categoria. É preciso que se proceda a uma adequação dogmática que leve em consideração as peculiaridades do subsistema em que se pretende que opere a culpabilidade. O primeiro passo é eleger como fundamento material da culpabilidade a responsabilidade, que se apresenta como a melhor perspectiva de análise, posto compatível com um sistema garantista e democrático de responsabilização penal. O princípio da alteridade, e não a presunção de liberdade, é que fundamentará a responsabilidade, de modo 
que o dever de reconhecimento do outro e respeito a ele terão preponderância nesta análise, ponto este de extrema relevância para o âmbito socioeducativo.

4.4.1. Pensada como um juízo de responsabilidade, a culpabilidade não poderá se prestar para agravar sofrimentos pessoais de maneira desnecessária. Deverá, no entanto, considerar o sujeito culpável inserido no mundo real, ou seja, considerará o processo de socialização do indivíduo, dentre outras circunstâncias pessoais, tais como o grau de participação democrática do sujeito, pois esta determina as possibilidades de um juízo legítimo de culpabilidade. Esse aspecto assume relevância no Direito Penal Juvenil, pois o sujeito culpável, neste âmbito, normalmente possui baixa participação democrática, do que decorre que a culpabilidade neste caso deve sempre ser benéfica ao adolescente.

4.5. A culpabilidade deve apresentar-se como limite da medida socioeducativa, orientando o Estado Democrático de Direito a conter seu poder punitivo. Como elemento do ato infracional, sua análise repousa na verificação de causas de exculpação, que deverá observar as peculiaridades do sistema em que agora opera.

4.5.1. A imputabilidade etária, constitucionalmente reconhecida, não é um obstáculo a análise da culpabilidade no Direito Penal Juvenil. É, na verdade, uma garantia fundamental do adolescente de que não poderá incidir o Direito Penal no momento de sua responsabilização, mas, sim, seu sistema próprio, no caso o Direito Penal Juvenil. Neste, é de se reconhecer uma imputabilidade própria ao adolescente - sujeito entre 12 e 18 anos de idade - que habilita a incidência das regras de responsabilização contidas no ECA, a partir da observância de todos os princípios do Direito Penal Juvenil.

4.5.1.2. Também ao adolescente deve ser reconhecida inimputabilidade por razões psíquicas, o que faria incidir a normativa da Lei Antimanicomial, a partir da execução prevista na Lei do Sinase.

4.5.2. A potencial consciência da ilicitude e seus desdobramentos no reconhecimento das hipóteses de erro no caso do Direito Penal Juvenil deve considerar o fato de que o adolescente é sujeito ainda em desenvolvimento, submetido a um referencial normativo plural, em razão da diversidade dos contextos socioeconômicos e culturais.

4.5.3. No campo do Direito Penal Juvenil as hipóteses em que não se pode exigir conduta distinta dos adolescentes são mais específicas que no campo do Direito Penal. No caso da coação moral, é de se considerar que o adolescente possui uma menor capacidade de resistência à coação. Já em relação à obediência hierárquica, no âmbito do Direito Penal Juvenil ao menos duas hipóteses especificas despontam: a influência da família ou figuras de autoridade e a inserção de muitos jovens no âmbito de organizações criminosas, não como bem se sabe, 
líderes, mas como mão de obra, normalmente para o tráfico. Outrossim, a falta de motivabilidade deve ser reconhecida como hipótese de inexigibilidade de conduta no âmbito da Justiça Juvenil.

4.6. A culpabilidade deve ser reconhecida também como circunstância de aplicação da medida socioeducativa. Muito embora não haja uma disciplina rígida para a aplicação das sanções no âmbito do Direito Penal Juvenil, há na legislação específica balizas para tal atividad que, se interpretadas a partir dos mecanismos de contenção do poder punitivo, tal qual a culpabilidade, são capazes de orientar uma responsabilização justa e garantista.

4.7. A análise da culpabilidade do adolescente em conflito com a lei se mostra, portanto, como um importante passo rumo à superação da crise de interpretação que se observa em relação ao ECA, pois possibilita limites maiores ao poder punitivo, tornando inconciliáveis os discursos que atualmente operam em parte da Justiça Juvenil, em que, a pretexto de observar os princípios do ECA, fazem vigorar uma lógica similar à tutelar.

4.8. A Justiça Juvenil se funda hoje no que foi denominado por Eduardo Gutierrez Cornelius ${ }^{1}$, como o pior dos dois mundos: menor proteção processual com maior controle penal, o que nada se diferencia, na prática, do que ocorria na etapa de caráter tutelar, pois, conquanto as condutas que ensejem a privação de liberdade, hoje, sejam unicamente as consideradas como delitos, verifica-se que, sem a análise de, por exemplo, as causas de exclusão da culpabilidade, adolescentes continuam sendo punidos por condutas que, no âmbito do Direito Penal, um adulto não seria.

4.8.1. Logo, o reconhecimento do Direito Penal Juvenil e, conjuntamente, da culpabilidade, se mostra como a opção mais provável de fazer frente aos arbítrios que ainda hoje imperam. De certo que garantias do sucesso nunca podem ser dadas, sobretudo quando se trata de assunto que ainda tem muitas nuances a serem analisadas. Contudo, dentre as possibilidades que se apresentam e, face à realidade que vive a Justiça Juvenil brasileira, a proposta apresentada pelo Direito Penal Juvenil, notadamente o limite que ela representa, tornam este um caminho mais seguro em relação aos demais.

\footnotetext{
${ }^{1}$ CORNELIUS, Eduardo Gutierrez. O pior dos dois mundos? A construção legítima da punição de adolescentes no Superior Tribunal de Justiça. São Paulo: IBCCRIM, 2018.
} 



\section{REFERÊNCIAS}

ANDRADE, Vera Regina Pereira de. Do paradigma etiológico ao paradigma da reação social: mudança e permanência de paradigmas criminológicos na ciência e no senso comum. Sequência, Florianopolis, v. 16, n. 30, p. 24-36, 1995.

Minimalismos e abolicionismos: a crise do sistema penal entre a deslegitimação e a expansão. Revista da Esmesc, Florianópolis, v. 13, n. 19, p. 163-182, 2006.

ANGOTTI, Bruna. Breves notas sobre o abolicionismo penal. Revista Brasileira de Ciências Criminais, São Paulo, v. 80, p. 247-279, set./out. 2009, online, não paginado.

ANISTIA INTERNACIONAL Você matou meu filho!: homicídios cometidos pela polícia militar no Rio de Janeiro. Rio de Janeiro: Anistia Internacional, 2015, disponível em $<$ https://anistia.org.br/wp-content/uploads/2015/07/Voce-matou-meu-filho_AnistiaInternacional-2015.pdf> Acesso: em 20 nov. 2018.

ANITUA, Gabriel Ignacio. Histórias dos pensamentos criminológicos. Rio de Janeiro: Revan;Instituto Carioca de Criminologia, 2008.

ATLAS DA VIOLÊNCIA 2017, disponível em $<$ http://www.ipea.gov.br/portal/images/170609_atlas_da_violencia_2017.pdf $>$, Acesso em: 20 nov. 2018

ATLAS DA VIOLÊNCIA 2018, disponível em $<$ http://www.ipea.gov.br/portal/images/stories/PDFs/relatorio_institucional/180604_atlas_da violencia_2018.pdf>, Acesso em: 20 nov. 2018.

BADARÓ, Gustavo. Processo Penal. Rio de Janeiro: Elsevier, 2012, p.42.

BARATTA, Alessandro. Criminologia crítica e crítica do Direito Penal: introdução à sociologia do direito penal. Tradução de Juarez Cirino dos Santos. 6. ed. Rio de Janeiro: Revan; Instituto Carioca de Criminologia, 2016.

Elemento de un nuevo derecho para la infancia y la adolescência. A proposito del Estatuto de Niño y del Adolescente de Brasil. Revista Ius et Veritas, Lima, v.10, p.73-79, 1995.

Funções instrumentais e simbólicas do Direito penal: lineamentos de uma teoria do bem jurídico. Revista Brasileira de Ciências Criminais, São Paulo, ano 2, n. 5, p. 5-24, 1994.

Funções instrumentais e simbólicas do Direito penal: lineamentos de uma teoria do bem jurídico. Revista Brasileira de Ciências Criminais, São Paulo, ano 2, n. 5, p. 5-24, 1994.

BASUALTO. Héctor Hernández. El nuevo Derecho Penal de adolescentes y la necesária revisión de su teoria del delito. Revista de Derecho, Valvidia v. XX, n. 2, p. 195-217, dez. 2007.

BATISTA, Nilo. Cem anos de reprovação. In: BATISTA, Nilo; NASCIMENTO, André. Cem anos de reprovação. Rio de Janeiro: Revan, 2011. 
. Introdução crítica ao direito penal brasileiro. 12. ed., rev. e atual. Rio de Janeiro:

Revan, 2011.

BATISTA, Nilo; ZAFFARONI, Eugênio Raúl et al. Direito Penal brasileiro, I. 3. ed. Rio de Janeiro: Revan, 2006.

BATISTA, Vera Malaguti. Difíceis ganhos fáceis. Drogas e juventude pobre no Rio de Janeiro. Rio de Janeiro: Revan, 2003.

. Introdução crítica à Criminologia brasileira. Rio de Janeiro: Revan, 2011.

BECKER, Howard. Outsiders: estudos da sociologia do desvio. Rio de Janeiro: Jorge Zahar, 2008.

BELOFF, Mary. Los sistemas de responsabilidad penal juvenil en América Latina. In GARCÍA MÉNDEZ, Emilio; BELLOF, Mary. (Comp.). Infancia, Ley y Democracia en América Latina. Analisis crítico del panorama legislativo en el marco de la Convención Internacional sobre los Derechos del Niño (1990-1998). Bogotá: Temis/Depalma.

BERGAMO, Marlene; HERNANDES, Raphael; MARIANI, Daniel; e RODRIGUES, Arthur. Mapa da morte. Folha de São Paulo, São Paulo, 16/10/2017.

$<$ http://temas.folha.uol.com.br/mapa-da-morte/jovens-vitimas/policia-de-alckmin-mata-1adolescente-por-semana-na-cidade-de-sao-paulo.shtml>, Acesso: em 20 nov. 2018.

BINDING, Karl. La culpabilidad em Derecho Penal. Traducción de Manuel Cancio Meliá. Montevidéu; Buenos Aires: Editorial B de f, 2009.

BITENCOURT, Cézar Roberto. Algumas controvérsias da culpabilidade na atualidade. In: FAYET JÚNIOR, Ney. CORRÊA, Simone Prates Miranda. (Orgs). A sociedade, a violência e o Direito Penal. Porto Alegre: Livraria do Advogado, 2000.

BITENCOURT, Cezar Roberto. Tratado de Direito Penal: parte geral 1. 21. ed. rev., ampl. e atual. São Paulo: Saraiva.

BORGHI, Adriana Pádua; FRASSETO, Flávio Américo. A noção de responsabilização no sistema de Justiça Juvenil: notas históricas sobre sua emergência, impasses e desafios. Revista Brasileira de Ciências Criminais, São Paulo, ano 22, vol. 126, p. 147-180, jul./ago. 2014.

BRAGA, Ana Gabriela Mendes. Reintegração social: discursos e práticas na prisão - um estudo comparado. 2012. Tese (Doutorado em Direito Penal) - Faculdade de Direito, Universidade de São Paulo, São Paulo, 2012. p. 34. Disponível em :

<file:///C:/Users/ana_c/Downloads/TESE_Ana_Gabriela_Mendes_Braga.pdf>. Acesso em: $15 / 01 / 2018$

BRANDÃO, Cláudio. A culpabilidade na dogmática penal. In: MENDES, Gilmar Ferreira. BOTTINI, Pierpaolo Cruz. PACELLI, Eugênio. (Coords). Direito Penal Contemporâneo: Questões controvertidas. São Paulo: Saraiva, 2011.

BRITO, Alexis Couto de; VANZOLINI, Maria Patrícia. Direito Penal: aspectos jurídicos controvertidos. São Paulo: Quartier Latin, 2006. 
BROIDE, Jorge; ROSA, Miriam Debieux; e VICENTIN, Maria Cristina G. Direitos Humanos e interfaces psi-jurídicas: uma pauta ético-política para questões dos adolescentes "perigosos". In DOTTO, Karen Meira; ENDO, Paulo Cesar; SPOSITO, Sandra Elena; e ENDO, Teresa Cristina (orgs.) Psicologia, violência e direitos humanos. São Paulo: CRP SP, 2011, p.78-94.

BRUÑOL, Miguel Cillero. "Nulla poena sine culpa". Um limite necessario al castigo penal de los adolescentes. In MÉNDEZ, Emilio García. Adolescentes y Responsabilidad Penal. Buenos Aires: Ad-Hoc, 2001.

BUSATO, Paulo Cesar. Apontamentos sobre o dilema da culpabilidade penal. Revista Liberdades, São Paulo, n. 8, p. 45-87, set./dez., 2011. Disponível em:

<http://www.revistaliberdades.org.br/site/outrasEdicoes/outrasEdicoesExibir.php?rcon_id=94

>. Acesso em: 10/09/2018.

CARVALHO, Salo de. A política criminal de drogas no Brasil: do discurso oficial as razões da descriminalização. 1996. Dissertação (Mestrado em Direito) - Universidade Federal de Santa Catarina, Florianópolis, 1996.

Antimanual de Criminologia. 5. ed. São Paulo: Saraiva, 2013.

2013.. Penas e medidas de segurança no Direito Penal brasileiro. São Paulo: Saraiva,

CARVALHO, Salo de; WEIGERT, Marina de Assis Brasil e. As alternativas às penas e às medidas socioeducativas: estudo comparado entre distintos modelos de controle social punitivo. Revista Discursos Sediciosos, Rio de Janeiro, ano 17, n. 19/20, p. 461-479, 2012.

COLUCCI, Camila Fernanda Pinsinato. Princípio do melhor interesse da criança: construção teórica e aplicação prática no direito brasileiro. 2014. Dissertação (Mestrado em Direito Civil) - Faculdade de Direito, Universidade de São Paulo, São Paulo, 2014.

CONDE, Francisco Muñoz. As duas faces de Edmund Mezger. Revista Justiça e Sistema Criminal, Curitiba, v. 5, n. 8, p. 9-24, jan./jun. 2013.

CONSELHO NACIONAL DE JUSTIÇA - CNJ. Relatório de Pesquisa. Dos espaços aos direitos: a realidade da ressocialização na aplicação de medidas socioeducativas de internação das adolescentes do sexo feminino em conflito com alei nas cinco regiões. Brasília: CNJ, 2015 .

CORNELIUS, Eduardo Gutierrez. O pior dos dois mundos? A construção legítima da punição de adolescentes no Superior Tribunal de Justiça. São Paulo: IBCCRIM, 2018.

CORRÊA JÚNIOR, Alceu; SHECAIRA, Sérgio Salomão. Pena e Constituição: aspectos relevantes para sua aplicação e execução. São Paulo: Revista dos Tribunais, 1995

COSTA, Ana Paula Motta. As garantias processuais e o direito penal juvenil como limite na aplicação da medida socioeducativa de internação. Porto Alegre: Livraria do Advogado, 2005;

Os adolescentes e seus direitos fundamentais: da invisibilidade à indiferença. Porto Alegre: Livraria do Advogado. 
COUSO, Jaime. La especialidad del Derecho Penal de adolescentes. Fundamentos empíricos y normativos y consecuencias para una aplicación diferenciada del Derecho Penal sustantivo. Revista de Derecho de la Pontificia Universidad Católica de Valparaíso, Valparaiso,

XXXVIII, p. 267-318, 2012.

CRAIDY, Carmen M; GONÇALVES, Ana Lemos. Medida Socioeducativa: da repressão à educação. Porto Alegre: Ed. UFRGS, 2005.

Dados disponíveis em <http://www.sdh.gov.br/noticias/pdf/levantamento-2013 >. Acesso em 20 nov. 2018.

DAUD, Rafael Rocha. Regra é regra. Revista Brasileira de Ciências Criminais, São Paulo, v. 109, p. 91-107, jul./ago. 2014.

DIGÁCOMO, Murilo. Garantias processuais do adolescente autor de ato infracional - o procedimento para apuração de ato infracional à luz do Direito da Criança e do Adolescente. In: : ILANUD; ABMP; SEDH; UNFPA. (Orgs.) Justiça, Adolescente e Ato Infracional: socioeducação e responsabilização. São Paulo: ILANUD, 2006. Disponível em <http://www.crianca.mppr.mp.br/arquivos/File/publi/ilanud/book_just_adol_ato_infrac.pdf $>$. Acesso em 15 dez. 2018;

DINU, Vitória Caetano Dreyer; MACHADO, Érica Babini L. do Amaral; SOBRAL NETO, Maurilo Miranda. Normalização e sujeição - Finalidades da medida socioeducativa de internação para adolescentes em conflito com a lei - Um estudo com sentenças em Pernambuco. Revista Brasileira de Ciências Criminais, São Paulo, v. 126, p. 37-66, 2016.

disponível em < http.//www.unespciencia.com.br/2014/03/unespcienci-50/> , p. 20. Acesso em 20/11/2018.

DOMINGO, Cíntia Oliveira. Adolescente e maioridade penal: reflexões sobre violência e prevenção à luz da proteção integral. Curitiba: Juruá, 2016.

DONATO, Giancarlo Fontoura. Sentença penal juvenil: em busca da proporcionalidade na aplicação da medida socioeducativa. Rio de Janeiro: Lumen Juris, 2015.

DOTTI, René Ariel. Algumas notas sobre o oráculo da culpabilidade. In: BATISTA, Nilo; NASCIMENTO, André. Cem anos de reprovação. Rio de Janeiro: Revan, 2011.

FAUTH, Isabel C. F. A reincidência criminal e a culpabilidade pela vulnerabilidade. In: AZEVEDO, Rodrigo G. de; CARVALHO, Salo de. (Orgs.) A crise do processo penal e as novas formas de administração da Justiça Criminal. Porto Alegre: Notadez, 2006.

FERRAJOLI, Luigi. A pena em uma sociedade democrática. Discursos Sediciosos, Rio de Janeiro, n. 12, p. 31-39, 2002.

Direito e Razão: Teoria do Garantismo Penal. Tradução Ana Paula Zomer Sica e outros. São Paulo: Revista dos Tribunais, 2002.

FERRAZ, Hamilton Gonçalves. A culpabilidade no Direito Penal Juvenil. Belo Horizonte: D’Plácido, 2017. 
FRANK, Reinhard. Sobre la estrutura del concepto de culpabilidad. Tradução de Gustavo Eduardo Aboso e Tea Löw. Montevidéu; Buenos Aires: Ed. B. de F., 2000.

FRASSETO, Flávio Américo; JOIA, Julia Hatakeyama. Internações psiquiátricas involuntárias e compulsórias: apontamentos sobre as responsabilidades do sistema de justiça e do sistema de saúde. Revista Brasileira de Ciências Criminais, São Paulo, v. 109, p. 227-257, jul./ago. 2014.

FREUDENTHAL, Berthold. Culpabilidad y reproche em el derecho penal. Traducción y prólogo: José Luis Guzmán Dalbora. Montevidéu; Buenos Aires: Editorial B de f, 2003, p.77.

FULLER, Paulo Henrique Aranda; DEZEM, Guilherme Madeira; MARTINS, Flávio. Estatuto da criança e do adolescente. 3. ed. São Paulo: Revista dos Tribunais, 2013.

GISI, Bruna; TONCHE, Juliana; ALVAREZ, Marcos Cesar; OLIVEIRA, Thiago. Entrevista com Álvaro Pires. A teoria da "racionalidade penal moderna" e os desafios da justiça juvenil. PLURAL: Revista do Programa de Pós-Graduação em Sociologia da USP, São Paulo, v. 24.1, p. 124-160, 2017.

GOLSCHMIDT, James. La concepción normativa dela culpabilidad. Traducción de Margarethe de Goldschmidt y Ricardo C. Núñez. Montevidéu;Buenos Aires: Editorial B de f, 2002.

GRECO, Luís. A ilha de Kant. In: GRECO, Luís; MARTINS, Antonio. (Orgs.) Direito Penal como Crítica da Pena: Estudos em homenagem a Juarez Tavares por seu $70^{\circ}$ Aniversário em 2 de setembro de 2012. São Paulo: Marcial Pons, 2012.

HALL, Stuart; JEFFERSON, Tony. (Orgs.) Rituales de resistência: subculturas juveniles em la Gran Bretaña de postguerra. Traducción de A. Nicolás Miranda, Rodrigo O. Ottonello y Fernando Palazzolo. Madrid: Traficantes de sueños, 2014.

HASSEMER, Winfred. Los jóvenes en el Derecho pena. Conferencia de apertura para el $26^{\circ}$ Congresso Alemán de Tribunales Juveniles. Publicado originalmente em ZJJ 4/2004. Estudio de Derecho Penal Juvenil, Santiago de Chile, ano IV, n, 13, nov. 2013.

Introdução aos fundamentos do Direito Penal. Tradução de Pablo Rodrigo Alflen da Silva. Porto Alegre: Sergio Antonio Fabris, 2005.

Persona, Mundo y Responsabilidad: Bases para una teoría de la imputación en Derecho Penal. Traducción de Francisco Muñoz Conde y Maria del Mar Díaz Pita. Valencia: Tirant lo Blanch, 1999.

HOYER, Andreas. Accesibilidad normativa como elemento de la culpabilidad. Traducción de Fernando Guanarteme Sanchez Lázaro. In: CALATAYUD, Manuel Maroto. Neurociencias y Derecho Penal: nuevas perspectivas em el ámbito de la culpabilidad y tratamento jurídicopenal de la peligrosidad. Montevideo; Buenos Aires: Editorial B de f, 2013.

INSTITUTO DE SEGURANÇA PÚBLICA. Balanço das incidências criminais e administrativas no Estado do Rio de Janeiro (ano base 2014). Rio de Janeiro: Governo do Rio de Janeiro, 2015, < http://arquivos.proderj.rj.gov.br/isp_imagens/uplods/BalancoAnual2015.pdf $>$ Acesso em 20/11/2018. 
INSTITUTO SOU DA PAZ. Aí eu voltei para o corre: Estudo da reincidência infracional do adolescente no estado de São Paulo. São Paulo: Instituto Sou da Paz, 2018. Disponível em <http://www.soudapaz.org/upload/pdf/ai_eu_voltei_pro_corre_2018.pdf > . Acesso em 29 nov. 2018.

ISHIDA, Válter Kenji. Estatuto da criança e do adolescente: doutrina e jurisprudência. 16. ed. São Paulo: Atlas, 2015.

JAKOBS, Günther. Dogmática de Derecho penal y la configuración normativa de la sociedade. Traducción de Javier Sánchez-Vera Gómez-Trelles. Madrid: Civitas, 2004.

. Fundamentos do Direito Penal. 2. ed. rev. São Paulo: Revista dos Tribunais, 2012.

. La imputación jurídico-penal y las condiciones de vigencia de la norma. In:

GOMES-JARA DIEZ, Carlos. (Coord.). Teoría de Sistema y Derecho Penal - Fundamentos y Possibilidades de Aplicación. Traducción de Javier Sánchez-Vera Gómez-Trelles y Carlos Gomes-Jara Díez. Granada: Comares, 2005

. Sociedade, Norma y Persona en uma teoria de um Derecho Penal funcional. Traducción de Manuel Cancio Meliá y Bernardo Feijóo Sánchez. Madrid: Civitas, 2000.

JUNQUEIRA, Gustavo Octaviano Diniz. Liberdade, culpabilidade e individualização da pena. 2009. Tese (Doutorado Direito Penal) - Pontifícia Universidade Católica de São Paulo, São Paulo, 2009.

KINDHÄUSER, Urs; MAÑALICHI R., Juan Pablo. Pena y Culpabilidad en el Estado democrático de derecho. Montevideo; Buenos Aires: Editorial B de F, 2011.

KONZEN, Affonso Armando. Pertinência socioeducativa: reflexões sobre a natureza jurídica das medidas. Porto Alegre: Livraria do Advogado, 2005;

LIBERATI, Wilson Donizeti. Adolescente e ato infracional - Medida Socioeducativa é pena? 2. ed. São Paulo: Malheiros Editores, 2012.

. Execução de medida socioeducativa em meio aberto: prestação de serviços à comunidade e liberdade assistida. In: ILANUD; ABMP; SEDH; UNFPA. (Orgs.) Justiça, Adolescente e Ato Infracional: socioeducação e responsabilização. São Paulo: ILANUD, 2006. Disponível em

<http://www.crianca.mppr.mp.br/arquivos/File/publi/ilanud/book_just_adol_ato_infrac.pdf $>$. Acesso em 9 out. 2018.

LUCHETE, Felipe. Jovem que foi recrutado pelo tráfico não deve ser punido, diz desembargador. CONJUR, 2/09/2016. Disponível em: < https://www.conjur.com.br/dl/jovemvende-droga-não-comete-ato.pdf>. Acesso em 20 dez. 2018.

MACHADO, Érica Babini L. do Amaral; SOBRAL NETO, Maurilo Miranda; DINU, Vitória Caetano Dreyer. Normalização e sujeição - Finalidades da medida socioeducativa de internação para adolescentes em conflito com a lei - Um estudo com sentenças em Pernambuco. Revista Brasileira de Ciências Criminais, ano 24, vol. 126, p. 37-66, dez. 2016. 
MAPA DA VIOLÊNCIA 2015, disponível em <http://

www.mapadaviolencia.org.br/pdf2015/mapaViolencia2015_adolescentes.pdf > Acesso em: 20 nov. 2018.

MAPA DA VIOLÊNCIA 2016, disponíveis em <https://www.mapadaviolencia.org.br/pdf2016/Mapa2016_armas_web.pdf > Acesso em: 20 nov. 2018.

MÁRQUEZ, Beatriz Cruz. Presupuestos de la responsabilidad penal del menor: una necesaria revisión desde la perspectiva adolescente. AFDUAM - Anuário de la Faculdad de Derecho de la Universidad Autónoma de Madrid, n. 15, p. 241- 269, 2011.

MARTÍN, Adán Nieto. Culpabilidad y Constitución. Derecho \& Sociedad, Lima, n. 32, p. 215-227, 2009. Disponível em

<http://revistas.pucp.edu.pe/index.php/derechoysociedad/article/viewFile/17427/17707>.

Acesso em: 18/07/2018.

MARTINS, Antonio. Culpabilidade como instituição política: um esboço. In: GRECO, Luíz ; MARTINS, Antonio. (Orgs) Direito Penal como Crítica da Pena: Estudos em homenagem a Juarez Tavares por seu $70^{\circ}$ Aniversário em 2 de setembro de 2012. São Paulo: Marcial Pons, 2012.

MASSA, Patrícia Helena. A menoridade penal no Direito brasileiro. Revista Brasileira de Ciências Criminais, ano 1, n. 4, p.126-132, out./dez. 1993.

MATSUDA, Fernanda Emy. A medida da maldade: periculosidade e controle social no Brasil.2009. Dissertação (Mestrado em Sociologia) - Faculdade de Filosofia, Letras e Ciências Humanas, Universidade de São Paulo, São Paulo, 2009.

MAURACH, Reinhart. A teoria da culpabilidade no direito penal alemão. Revista Brasileira de Criminologia e Direito Penal, Rio de Janeiro n. 15, v. 4, p. 19-36, 1966.

MAYER, Max Ernest. Derecho Penal: Parte General. Traducción por Sergio Politoff Lipschitz. Montevidéu; Buenos Aires: Editorial B de f., 2007.

MELO JÚNIOR, Luiz Cláudio Moreira. A teoria dos sistemas sociais em Niklas Luhmann. Sociedade e Estado. Brasília, v. 28, n. 3, Brasília, set./dez. 2013, 716. Disponível em http://www.scielo.br/scielo.php?script=sci_arttext\&pid=S0102-69922013000300013 >. Acesso em: 21/10/2018.

MELO, Eduardo Rezende. Critérios para o recebimento da representação e para a fixação da medida socioeducativa na Lei 12.954/2012. Revista Brasileira de Ciências Criminais, São Paulo, v. 109, p.209-226, jul./ago. 2014.

MÉNDEZ, Emilio García. A responsabilidade penal juvenil na encruzilhada. Boletim IBCCRIM, São Paulo, ano 23, n. 271, jun. 2015.

Adolescentes e Responsabilidade Penal: um debate Latino-Americano. Disponível em <http://www.egov.ufsc.br/portal/sites/default/files/anexos/11143-11143-1-PB.pdf〉. Acesso em: 20/04/2017. 
. La privación de libertad como forma de "proteccion"de la infancia: un caso paradigmático de construccion judicial de vulnerabilidade. Revista Brasileira de Ciências Criminais, São Paulo, v. 109, p. 133-145, jul./ago. 2014.

Para uma historia del control penal de la infancia: la informalidade de los mecanismos formales de control social. In RAMÍREZ, Juan Busto. Um Derecho Penal del Menor. Santiago de Chile: Editorial Jurídica ConoSur Ltda., 1992.

Problemas centrales de la responsabilidad penal juvenil em America Latina. In Justiça Juvenil na Contemporaneidade. COSTA, Ana Paula Motta; e EILBERG, Daniela Dora (orgs). Porto Alegre: DM, 2015.

MERCURIO, Ezequiel. Cerebro y adolescencia: implicancias jurídico-penales. Buenos Aires: Ad.Hoc, 2012.

MEZGER, Edmund. Tratado de Derecho Penal. Traducción de la 2. edición Alemana (1933) por José Arthuro Rodríguez Muñoz. Madrid: Editorial Revista de Derecho Privado.

MINAHIM, Maria Auxiliadora. Direito Penal da emoção: a inimputabilidade do menor. São Paulo: Revista dos Tribunais, 1992.

. Tratamento jurídico-penal das infrações penais praticadas por adolescentes: Uma terceira via. Duc In Altum - Cadernos de Direito, Recife, vol. 7, n. 12, p. 75-103, mai./ago. 2015.

. Tratamento jurídico-penal das infrações penais praticadas por adolescentes: Uma terceira via. Duc In Altum - Cadernos de Direito, Recife, vol. 7, n. 12, p. 75-103, mai./ago. 2015, p.89.

MUÑOZ CONDE, Francisco.; GARCIA ARÁN, Mercedes. Derecho penal: parte general. 8. ed. Valencia: Tirant lo blanch, 2010.

NICODEMOS, Carlos. A natureza do sistema de responsabilização do adolescente autor de ato infracional. In: ILANUD (Org.) Justiça, adolescente e ato infracional: socioeducação e responsabilização. São Paulo: ILANUD, 2006.

PACELLI, Eugênio. O princípio da culpabilidade nas concepções de Roxin e Jakobs: análise e comparação. Disponível em: <https://eugeniopacelli.com.br/o-principio-de-culpabilidadenas-concepcoes-de-roxin-e-jakobs-analise-e-comparacao/>. Acesso em: 19/10/2018.

PASSETTI, Edson. Louk Hulsman e o abolicionismo libertário. In: BATISTA, Nilo; KOSOVSKI, Ester. (Orgs). Tributo a Louk Hulsman. Rio de Janeiro: Revan, 2012.

PAULA, Paulo Afonso Garrido. A natureza do sistema de responsabilização do adolescente autor de ato infracional. In: ILANUD (Org.) Justiça, adolescente e ato infracional: socioeducação e responsabilização. São Paulo: ILANUD, 2006.

PAVARINI, Massimo. Control y dominación: teorias criminológicas burguesas y proyecto hegemônico. Traducción de Ignacio Muñagorri. Buenos Aires: Siglo XXI Editores Argentina, 2002. 
PÉREZ MANZANO, Mercedes. Culpabilidad y prevención: las teorias de la prevención general positiva en la fundamentación de la imputación subjetiva y de la pena. Madrid: Ediciones de la Universidad Autónoma de Madrid, 1989.

PESCE LAVAGGI, Eduardo A. Aproximación al estudio de la culpabilidad en el Derecho Penal Juvenil. Revista de Ciencias Penales, Montevideo, v. 4, 1998, p. 362.

PINTO, Tatiana Vargas. La determinación judicial de la sanción penal juvenil. Revista de Derecho de la Pontificia Universidad Católica de Valparaíso, Valparaíso, XXXIV, p. 475$501,1^{\circ}$ semestre, 2010.

PIRES, Álvaro. A racionalidade penal moderna, o público e os direitos humanos. Novos Estudos Cebrap, São Paulo, n. 68, p. 39-60, mar. 2004.

PRADO, Luiz Régis. Curso de Direito Penal Brasileiro. 14. ed. rev. e ampl. São Paulo: Revista dos Tribunais, 2015.

RAMIDOFF, Mário Luiz. Direito penal juvenil: quem garante os jovens desta bondade punitiva. Revista da ESMESC - Escola Superior da Magistratura do Estado de Santa Catarina, Florianópolis, v. 9, n. 15, p. 152-155, 2003.

RAMÍREZ, Juan Bustos. Imputabilidad y edad penal. Disponível em:

$\langle$ http://iin.oea.org/Cursos_a_distancia/imputabilidad_y_edad_penal.pdf $>$. Acesso em 20 nov. 2018.

REALE JÚNIOR, Miguel. Teoria do delito. 2. ed. rev. São Paulo: Editora Revista dos Tribunais, 2000.

RODRIGUES, Ellen Cristina Carmo. A Justiça Juvenil no Brasil e a responsabilidade penal do adolescente: rupturas, permanências e possibilidades. 2016. Tese (Doutorado em Direito) - Faculdade de Direito, Universidade do Estado do Rio de Janeiro, Rio de Janeiro, 2016.

ROSA, Alexandre Morais da. Introdução crítica ao ato infracional. Princípios e garantias constitucionais. Rio de Janeiro: Lumen Juris, 2007.

ROSA, Miriam Debieux; PRUDENTE, Sergio Eduardo Lima. Responsabiliz(ação): o sujeito entre a responsabilidade e o dever jurídico. Revista Brasileira de Ciências Criminais, São Paulo, v. 109, p.75-89, jul./ago. 2014.

ROSSATO, Luciano Alves; LÉPORE, Paulo Eduardo, e CUNHA, Rogério Sanches. Estatuto da criança e do adolescente: Lei $\mathrm{n}^{\circ}$ 8069/90 comentado artigo por artigo. 7. ed. São Paulo: Saraiva, 2015.

ROXIN, Claus. A culpabilidade como critério limitativo da pena. Revista de Direito Penal. Rio de Janeiro, n. 11/12, p. 7-20, jul./dez., 1973.

A culpabilidade e sua exclusão no Direito Penal. In: GRECO, Luís. MIRANDA NETTO, Fernando Gama de. (Orgs.). Estudos de Direito Penal. 2. ed. Rio de Janeiro: RENOVAR, 2008. 
. A proteção de bens jurídicos como função do Direito Penal. Tradução e organização de André Luís Callegari e Nereu José Giacomolli. 2. ed. Porto Alegre: Livraria do Advogado, 2009.

. Culpa e responsabilidade. Revista Portuguesa de Ciência Criminal, Coimbra, n. 4, v. 1, p. 503-541, 1991.

Derecho Penal: parte general, tomo I. 2. ed. Traducción de Diego-Manuel Luzón Peña, Miguel Díaz y García Conlledo y Javier de Vicente Remesal. Madrid: Civitas, 1997.

SÁ, Alvino Augusto de. Criminologia clínica e psicologia criminal. 3. ed. São Paulo: Revista dos Tribunais, 2013.

SALAS, Jaime Couso. Sustitución y remisión de sanciones penales de adolescentes. Criterios y limites para las decisiones en sede de control judicial de las sanciones. In: Estudios de Derecho Penal Juvenil II. Santiago de Chile: Centro de Documentación Defensoría Penal Pública, diciembre 2011, p. 269-355.

SANTOS, Juarez Cirino dos. Direito Penal: parte geral. 7. ed. rev. atual. e ampl. Florianópolis: ICPC; Empório do Direito, 2017.

SARAIVA, João Batista Costa. Compêndio de Direito Penal Juvenil. 3 ed. rev., e ampl. Porto Alegre: Livraria do Advogado, 2006.

SCHMIDT, Fabiana. Adolescentes Privados de Liberdade: A dialética dos direitos conquistados e violados. Curitiba: Juruá, 2009.

SCHÜNEMANN, Bernard. La culpabilidad: Estado de la cuestión. Traducción de David Felip I Saborit y Ramon Ragués I Vallés. In: Universidad Pompeu Fabra (org.). Sobre el estado de la teoria del delito - Seminario em la Universidad Pompeu Fabra). Madrid: Civitas, 2000.

SHECAIRA, Sérgio Salomão. Criminologia. 3. ed. rev., atual. e ampl. São Paulo: Revista dos Tribunais, 2011.

\section{8.}

. Sistema de Garantias e o Direito Penal Juvenil. São Paulo: Revista dos Tribunais,

SILVA SÁNCHEZ, Jesús-María. La política criminal ante el hecho penalmente antijuridico cometido por un menor de edad. Revista Brasileira de Ciências Criminais, São Paulo, ano 4, n 13, p. 38-53, 1996.

SILVA, Antonio Armando do Amaral e. O Estatuto da Criança e do Adolescente e sistema de responsabilidade penal juvenil ou o mito da inimputabilidade penal. In: ILANUD (Org.)

Justiça adolescente e ato infracional: socioeducação e responsabilização. São Paulo:

ILANUD, 2006, p. 49-60;

SILVA, Virgílio Afonso da. Direitos Fundamentais: conteúdo essencial, restrições e eficácia. 2. ed. São Paulo: Malheiros Editores, 2010, p.43-56.

SOTOMAYOR, Carlos Tiffer. Fines y determinación de las sanciones penales juveniles. In: Estudios de Derecho Penal Juvenil II. Santiago de Chile: Centro de Documentación Defensoría Penal Pública, diciembre 2011, p. 11-43. 
SPOSATO, Karyna Batista. Duas questões fundamentais sobre a responsabilização penal de adolescentes. Boletim IBCCrim, São Paulo, v. 23, n. 271, jun. 2015.

Elementos para uma teoria da responsabilidade penal de adolescentes. 2011. Tese (Doutorado em Direito Público) - Universidade Federal da Bahia, Salvador, 2011. Disponível em <https://repositorio.ufba.br/ri/bitstream/ri/15283/1/Tese\%20\%20Karyna\%20Batista\%20Sposato.pdf>. Acesso em: 15/03/2017, p. 60-74.

O Direito Penal Juvenil. São Paulo: Revista dos Tribunais, 2006.

; MINAHIM, Maria Auxiliadora. A internação de adolescentes pela lente dos tribunais. Revista Direito GV, São Paulo, v. 7, n. 1, p. 277-298, 2011.

TANGERINO, Davi de Paiva Costa. Culpabilidade. 2. ed. São Paulo: Saraiva, 2014.

Pena é política. Revista Discursos Sediciosos: crime, direito e sociedade, Rio de Janeiro, ano 19, n. 21/22, 2014.

TAVARES, Juarez. Culpabilidade e individualização da pena. In: BATISTA, Nilo; NASCIMENTO, André. (Orgs.). Cem anos de reprovação. Rio de Janeiro: Revan, 2011.

TEIXEIRA, Alessandra; SALLA, Fernando. De menores a adolescentes infratores: contribuições ao debate sobre a criminalidade juvenil. Revista Brasileira de Ciências Criminais, São Paulo, n. 126, p. 267-289, 2016.

TEIXEIRA, Caroline Köhler. As medidas socioeducativas do Estatuto da Criança e do Adolescente e seus parâmetros normativos de aplicação. Revista da Emesc, Florianópolis, v. 20, n. 26, p. 151-202, 2013.

VALDIVIA, Dominique Nicole Tapia. Estudio del tratamento al adolescente enajenado mental em el proceso penal chileno. 2015. Dissertação de Memoria (Licenciatura en Ciencias Jurídicas y Sociales) - Facultad de Derecho, Universidad de Chile, Santiago, 2015.

VERONESE, Josiane Rose Petry. Direito Penal Juvenil e responsabilização estatutária: elementos aproximativos e/ou distanciadores? o que diz a Lei do Sinase: a imputabilidade penal em debate. Rio de Janeiro: Lumen Juris, 2015.

VILLAS-BÔAS, Eduardo da Silva. Direito Penal e o paradigma da responsabilidade juvenil. Salvador: EDUFBA, 2012.

VINCENTIN, Maria Cristina G.; PADILLA-GOMEZ, Alejandra; CATÃO, Ana Lucia. Notas sobre a responsabilidade desde os escritos de M. Foucault: pistas para pensar a Justiça Juvenil. Revista Brasileira de Ciências Criminais, São Paulo, v. 109, p. 21-46, jul./ago. 2014.

VON BELING, Ernest. Esquema de Derecho Penal: La doctrina del delito-tipo. Buenos Aires: Libreria El Floro, 2002.

VON LISZT, Franz. Tratado de Derecho penal. Traduzido da 20. ed. alemã por Luis Jimenez de Asúa. Madrid: Editorial Reus, 1927, t. II 
WELZEL, Hans. Estudios de Derecho Penal: estúdios sobre el sistema de derecho penal; causalidad y acción; Derecho penal y filosofia. Tradução de Gustavo Eduardo Aboso e Tea Löw. Montevide; Buenos Aires: Editorial B de f, 2003.

WOLKMER, Antonio Carlos. Pluralismo jurídico: fundamentos de uma nova cultura no direito. 3.ed. rev. e atual. São Paulo: Alfa Omega, 2001.

ZAFFARONI, Eugenio Raúl. Em busca das penas perdidas. 5. ed. Rio de Janeiro: Revan, 2012.

; PIERANGELI, José Henrique. Manual de direito penal brasileiro: parte geral. 3. ed. rev. e atual. São Paulo: Editora Revista dos Tribunais, 2001. 